\title{
A novel Bayesian method for dual-agent Phase I dose-escalation studies using penalized D-optimality
}

\author{
Graham Wheeler
}

\author{
From 2nd Clinical Trials Methodology Conference: Methodology Matters \\ Edinburgh, UK. 18-19 November 2013
}

In oncology, there is increasing interest in studying combinations of drugs to improve treatment efficacy and/or reduce harmful side-effects. Dual-agent Phase I clinical trials are primarily concerned with drug safety, with the aim to discover a maximum tolerated combination dose via dose-escalation; small cohorts of patients are given set doses of both drugs and monitored to see if any particular toxic reactions occur. Whether to escalate, de-escalate or maintain the current dose for either drug for subsequent cohorts is based on the number and severity of observed toxic reactions, and a decision rule.

We propose a novel Bayesian phase I trial design for the study of two chemotherapeutic agents in combination based on a penalized D-optimality criterion. Patients are allocated to dose combinations that provide the most information about the two agents in combination and their interactive behaviour, subject to a penalty function that doses patients at combinations with a probability of toxicity close to some desired target level. Such a criterion compromises between population gain (maximizing information) and patient gain (treating each patient at a maximally tolerable combination).

We show how the design can be applied to a dual-agent Phase I dose-escalation study of Paclitaxel and an Aurora Kinase Inhibitor in combination. Our simulation studies show that the method provides accurate and tolerable recommendations for further clinical testing and has the ability to outperform other proposed methods.

Published: 29 November 2013

MRC Biostatistics Unit, Cambridge, UK

(C) 2013 Wheeler; licensee BioMed Central Ltd. This is an Open Access article distributed under the terms of the Creative Commons Attribution License (http://creativecommons.org/licenses/by/2.0), which permits unrestricted use, distribution, and reproduction in any medium, provided the original work is properly cited.
doi:10.1186/1745-6215-14-S1-P41

Cite this article as: Wheeler: A novel Bayesian method for dual-agent Phase I dose-escalation studies using penalized D-optimality. Trials 2013 14(Suppl 1):P41.
Submit your next manuscript to BioMed Central and take full advantage of:

- Convenient online submission

- Thorough peer review

- No space constraints or color figure charges

- Immediate publication on acceptance

- Inclusion in PubMed, CAS, Scopus and Google Scholar

- Research which is freely available for redistribution Submit your manuscript at
www.biomedcentral.com/submit C BioMed Central 